\title{
Compósitos de Matriz Termofixa Fenólica Reforçada com Fibras Vegetais
}

\author{
Jane M. F. Paiva, Wanderson G. Trindade e Elisabete Frollini
}

Resumo: Neste trabalho, pré-polímeros do tipo fenólico ( resóis ) e lignina - fenol ( $40 \%$ w/w ) foram sintetizados e usados na preparação de matrizes em compósitos reforçados com diversas fibras vegetais : sisal, curaua e bagaço de cana-de açúcar, sendo as fibras previamente extraídas com cicloexano/ etanol. Os compósitos reforçados com sisal apresentaram um aumento significativo na resistência ao impacto, quando comparados com a matriz termofixa. As fibras de curaua foram submetidas a um tratamento adicional com $\mathrm{NaOH} 10 \%$, tendo os respectivos compósitos apresentado também resistência ao impacto superior ao da matriz fenólica não reforçada., enquanto que os compósitos reforçados com bagaço de cana de açúcar apresentaram pequena alteração nesta propriedade.

Palavras-chave: Compósitos, lignina, resina fenólica, fibras vegetais, resistência ao impacto.

\section{Introdução}

A aplicação de materiais lignocelulósicos como um componente de reforço em compósitos poliméricos tem recebido uma maior atenção particularmente por causa de seus baixos preço e peso específico, principalmente na indústria automobilística. ${ }^{[1]}$

Este desenvolvimento tem ocorrido porque os reforços lignocelulósicos oferecem várias vantagens em relação aos inorgânicos, isto é, baixa densidade, alta deformabilidade, baixa abrasividade aos moldes e aos equipamentos de mistura, apresentando ainda baixo custo. Além disso, os reforços baseados em cargas ou fibras lignocelulósicas são derivados de recursos renováveis. ${ }^{[1]}$

É bem conhecido que a compatibilidade do material lignocelulósico com a matriz possui um papel fundamental na determinação das proprie- dades do compósito. Os materiais lignocelulósicos possuem grupos hidroxila polares na superfície devido predominamente à celulose e à lignina, sendo que estes grupos polares têm grande facilidade em interagir com matrizes poliméricas polares, como no caso de resinas fenólicas. ${ }^{[1]}$

As fibras vegetais estão se tornando alternativas econômicas e ecológicas para uso como reforços e cargas em plásticos. Há quem preveja a gradual substituição de aditivos sintéticos tradicionais, particularmente fibras de vidro, por esses materiais, abrindo respeitáveis perspectivas de mercado para países de vocação agrícola. ${ }^{[2]}$

Dentre as propriedades de um material polimérico, duas podem ser destacadas devido a importância das mesmas: facilidade de fabricação e resistência ao impacto. A resistência ao impacto se torna muito importante porque falhas devido à cargas repentinas são muito comuns em condições de 
serviço e ocorrem até mais frequentemente do que quando as forças são aplicadas vagarosamente. Isto acontece porque as forças (cargas) de impacto são aplicadas tão rapidamente que as relaxações da estrutura molecular não acompanham o processo, resultando em fratura, ocasionada pela quebra da cadeia e/ou separação das interfaces. ${ }^{[3]}$

\section{Experimental}

Síntese: Foram sintetizados em solução aquosa pré-polímeros do tipo resol (fenólico) utilizando-se fenol, formaldeído (solução a 37\%) e hidróxido de potássio (1,0: 1,38: 0,06 massa/massa, respectivamente) sob refluxo a $70^{\circ} \mathrm{C}$ durante 60 minutos, com agitação mecânica. Após a síntese, o pré-polímero foi resfriado à temperatura ambiente e foi adicionado $\mathrm{HCl}$ até a neutralização. Foram sintetizados também pré-polímeros ligninafenol, substituindo-se $40 \%$ em massa do fenol por lignina (extraída do bagaço de cana pelo processo organossolve acetona/meio ácido), estabelecendose as mesmas condições de síntese.

Moldagem: Após a neutralização dos prépolímeros, extraiu-se a água a $40^{\circ} \mathrm{C}$ sob pressão reduzida. Em seguida, os pré-polímeros foram misturados com $10 \%$ em massa de resorcinol a $50^{\circ} \mathrm{C}$ com agitação mecânica durante 30 minutos e foram moldados por compressão em um molde de alumínio (dimensões: 219,7 mm de comprimento; $99,4 \mathrm{~mm}$ de largura e $6 \mathrm{~mm}$ de espessura), obtendo-se os polímeros termofixos fenólico e lignina-fenol. A moldagem por compressão foi realizada de acordo com um ciclo de moldagem pré-estabelecido (através de análises por DSC Calorimetria Exploratória Diferencial) até atingir a temperatura de $125^{\circ} \mathrm{C}$, na qual se manteve durante 90 minutos sob pressão de $50 \mathrm{Kgf} / \mathrm{cm}^{2}$ para o polímero termofixo fenólico e durante $120 \mathrm{mi}$ nutos e $50 \mathrm{Kgf} / \mathrm{cm}^{2}$ para o polímero lignina-fenol.

Para a obtenção dos compósitos fenólico e lignina-fenol contendo fibras de bagaço e dos compósitos contendo fibras de sisal, foram utilizadas fibras de bagaço de cana de comprimento 1,5 $\mathrm{cm}(7 \% \mathrm{massa} / \mathrm{massa})$ e fibras de sisal cortadas nos comprimentos $1,5 \mathrm{~cm}, 2 \mathrm{~cm}$ e $3 \mathrm{~cm}$ (15\% massa/ massa), as quais foram submetidas anteriormente à extração com cicloexano/etanol (1:1 v/v) em extrator soxlet durante 50 horas e após esta extração secadas em estufa com circulação de ar à temperatura de aproximadamente $60^{\circ} \mathrm{C}$. Esses compósitos também foram moldados por compressão no mesmo molde citado, sendo os pré-polímeros misturados com resorcinol (como descrito anteriormente) antes de serem adicionadas as fibras, as quais foram pré-impregnadas com a mistura pré-polímero/resorcinol sob agitação mecânica durante 30 minutos a $50^{\circ} \mathrm{C}$. $\mathrm{O}$ ciclo de moldagem utilizado para a obtenção dos compósitos fenólico e lignina-fenol (contendo fibras distribuídas aleatoriamente) foram os mesmos descritos para os respectivos polímeros termofixos.

Foram moldados também compósitos fenólico e lignina-fenol (mesmo procedimento anterior) utilizando-se fibras de curauá submetidas à extração com cicloexano/etanol e tratadas em solução de $\mathrm{NaOH}(10 \%)$ durante 60 minutos a $0^{\circ} \mathrm{C}$ (para evitar que ocorra degradação da celulose) e em seguida lavadas com água destilada em excesso até a neutralização.

Caracterização: Foram realizados ensaios de determinação de Dureza Shore D para os polímeros termofixos fenólico e lignina-fenol e os compósitos fenólico e lignina-fenol contendo fibras de bagaço de cana $(1,5 \mathrm{~cm})$ e contendo fibras de sisal (comprimentos: $1,5 \mathrm{~cm} ; 2 \mathrm{~cm}$ e $3 \mathrm{~cm}$ ) de acordo com a Norma ABNT NBR7456.

A partir de cada placa moldada foram cortados e lixados 10 corpos de prova sem entalhe (polímeros termofixos e compósitos) e foram realizados ensaios de impacto do tipo Izod em equipamento CEAST Resil 25 (com martelo instrumentado de 5,5 Joules e velocidade de $3,46 \mathrm{~m} / \mathrm{s}$ ) de acordo com a Norma ASTM D256.

Foram realizadas análises por MEV (Microscopia Eletrônica de Varredura), após ensaio de impacto, em amostras dos polímeros termofixos fenólico e lignina-fenol e compósitos fenólico e lignina-fenol contendo fibras de bagaço de cana e fibras de sisal em Microscópio Zeiss West Germany, modelo DSM 960, aceleração de elétrons de $20 \mathrm{kV}$. As amostras foram coladas em porta-amostras de alumínio, pintadas com tinta-prata e revestidas com uma fina camada de ouro.

\section{Resultados e Discussão}

Analisando-se os resultados (Figura 1) podese observar que os polímeros termofixos fenólico 


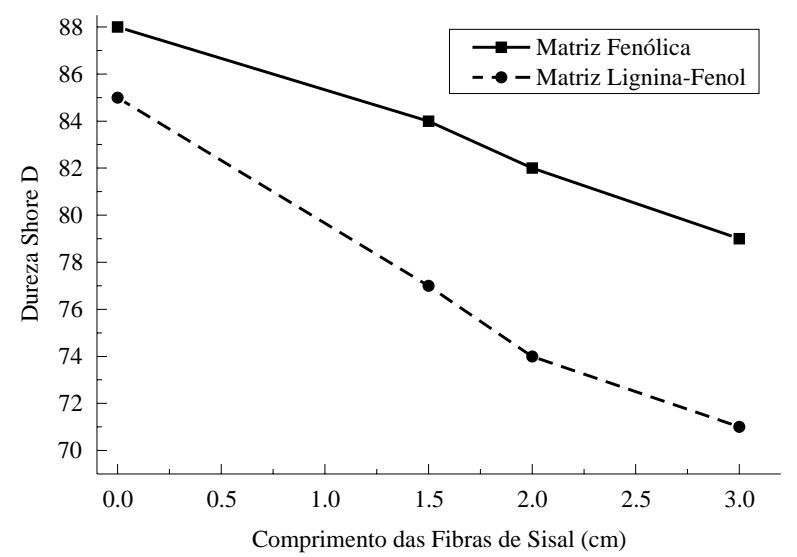

Figura 1. Variação da dureza dos polímeros fenólico e lignina-fenol e seus compósitos com fibras de sisal de $1,5 \mathrm{~cm} ; 2 \mathrm{~cm}$ e $3 \mathrm{~cm}$.

e lignina-fenol apresentaram valores de dureza mais altos quando comparados aos compósitos relacionados a estes, ou seja, todos os materiais apresentaram diminuição gradativa da dureza devido à introdução de fibras.

Estes resultados tanto podem indicar que a presença de fibras diminui a resistência mecânica à penetração de um outro corpo, como podem ser consequência da higroscopicidade das fibras. Esta propriedade acarreta um maior teor de umidade, e as moléculas de água teriam um efeito plastificante na superfície. Como o teste é realizado na superfície, as fibras podem ocasionar também maior absorção de umidade e menor dureza. Pode-se notar que a presença de lignina também leva a uma diminuição na dureza, o que pode ter a mesma explicação anterior.

Observando-se os polímeros termofixos fenólico e lignina-fenol (ou seja, as matrizes fenólica e lignina-fenol) e seus compósitos contendo fibras de sisal (Figura 1), nota-se que ocorreu diminuição da dureza quando foram utilizadas fibras de maior comprimento. Isto pode estar relacionado ao fato de que quanto maior o comprimento das fibras, maior é a presença destas numa determinada área da superfície e maior a probabilidade de serem atingidas pelo identor (durômetro) durante o ensaio destes compósitos.

Ressalta-se que o valor de dureza encontrado para o termofixo fenólico é compatível com o citado na literatura para um resol modificado com resorcinol (D89). ${ }^{[4]}$

Comparando-se os resultados encontrados para estes polímeros termofixos fenólico e lignina-fenol e os compósitos contendo fibras de bagaço de cana curados à temperatura de $125^{\circ} \mathrm{C}$ com os resulta-
Tabela 1. Resultados do Ensaio de Dureza Shore D.

\begin{tabular}{lcc}
\hline \multicolumn{1}{c}{ Material } & $\begin{array}{c}\text { Curados a } \\
\mathbf{T}=\mathbf{1 2 5}^{\circ} \mathbf{C}\end{array}$ & $\begin{array}{c}\text { Curados a } \\
\mathbf{T}=\mathbf{8 5}^{\circ} \mathbf{C}\end{array}$ \\
\hline $\begin{array}{l}\text { Polímero Termofixo } \\
\begin{array}{l}\text { Compósito Fenólico/fibra } \\
\text { de bagaço }(1,5 \mathrm{~cm})\end{array}\end{array}$ & $\mathrm{D} 88$ & $\mathrm{D} 82$ \\
$\begin{array}{l}\text { Polímero Termofixo } \\
\text { Lignina-fenol }\end{array}$ & D83 & D63 \\
$\begin{array}{l}\text { Comp. Lignina-fenol/ fibra } \\
\text { de bagaço }(1,5 \mathrm{~cm})\end{array}$ & D79 & D79 \\
\hline
\end{tabular}

dos encontrados em trabalho anterior (Tabela 1$)^{[5]}$, no qual os polímeros termofixos fenólico e ligninafenol e os compósitos com fibras de bagaço foram curados à temperatura de $85^{\circ} \mathrm{C}$; observa-se que os materiais curados a $\mathrm{T}=125^{\circ} \mathrm{C}$ apresentaram aumento na dureza. Isto está ligado ao fato de que quanto maior é a temperatura de cura, maior a extensão do entrecruzamento fazendo com que esses materiais e suas superfícies apresentem maior dureza.

Analisando-se os resultados do ensaio de impacto (Figura 2) observa-se que os polímeros termofixos fenólico e lignina-fenol apresentaram valores próximos $(12,8 \mathrm{~J} / \mathrm{m}$ e $13,3 \mathrm{~J} / \mathrm{m}$, respectivamente), indicando que a presença de lignina não alterou muito a propriedade de resistência ao impacto. Observou-se que o compósito fenólico/fibra de bagaço $(1,5 \mathrm{~cm})$ apresentou resistência ao impacto de $20,2 \mathrm{~J} / \mathrm{m}$ e o compósito lignina-fenol/ fibra de bagaço $(1,5 \mathrm{~cm})$ apresentou resistência ao impacto de $21,5 \mathrm{~J} / \mathrm{m}$, indicando uma certa melhoria nos resultados. Observou-se também que todos os compósitos contendo fibras de sisal (de comprimentos: $1,5 \mathrm{~cm}, 2 \mathrm{~cm}$ e $3 \mathrm{~cm}$ ) apresenta-

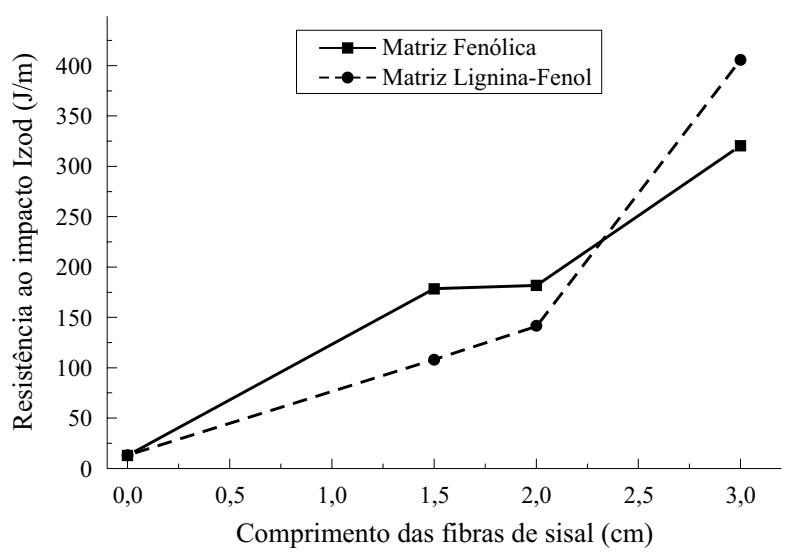

Figura 2. Variação da resistência ao impacto dos polímeros fenólico e lignina-fenol e seus compósitos com fibras de sisal de $1,5 \mathrm{~cm} ; 2 \mathrm{~cm}$ e $3 \mathrm{~cm}$. 
ram melhoria na resistência ao impacto (Figura 2) em relação à matriz fenólica e lignina-fenol (polímeros termofixos), ou seja, a energia necessária para quebrar os corpos-de-prova foi maior, revelando, portanto, que as fibras presentes nos compósitos não agem simplesmente como carga, mas sim como reforço.

De acordo com os resultados do ensaio (Figura 2) pode-se observar um grande aumento na resistência ao impacto dos compósitos contendo fibras de sisal, com destaque para aqueles contendo fibras mais longas $(3 \mathrm{~cm})$, sendo que o compósito fenólico/fibra de sisal apresentou resistência ao impacto de $320,4 \mathrm{~J} / \mathrm{m}$ e o compósito lignina-fenol/fibra de sisal apresentou resistência ao impacto de $405,8 \mathrm{~J} / \mathrm{m}$. Isto pode estar ligado ao fato de que as fibras de maior comprimento apresentaram uma maior capacidade de absorção e distribuição da energia do choque em alta velocidade. Ressalta-se que quanto mais longa a fibra, menor o número de pontas de fibra e menor o número de defeitos que essas pontas podem gerar no compósito como um todo. ${ }^{[6]}$

$\mathrm{Na}$ literatura encontra-se que compósitos de matriz termoplástica (polipropileno - PP) reforçados com sisal (60\% em volume) e bagaço de canade-açúcar (\% de fibra não informada) apresentam respectivamente resistência ao impacto de 102,49 e $58,22 \mathrm{~J} / \mathrm{m}$ (para amostras não-entalhadas). ${ }^{[7]}$

Em geral, os compósitos termofixos (ou termorrígidos) contendo fibras vegetais apresentam uma melhoria em suas propriedades mecânicas com o aumento do comprimento das fibras até um certo limite, pois pode ocorrer diminuição nos valores de propriedades, como a resistência à tra-

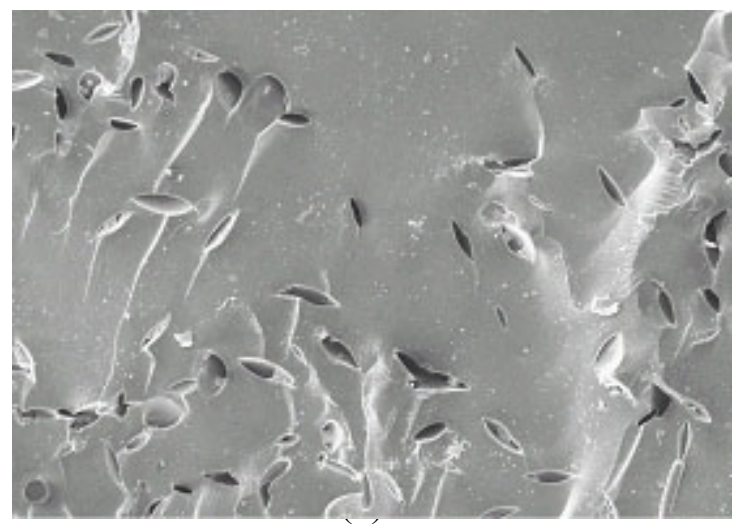

ção, com o aumento do comprimento de fibras, devido ao contato fibra-fibra que ocorre quando a fibra impregnada com resina líquida é prensada em moldes para preparar compósitos, em forma de placas ou laminados. ${ }^{[8]}$

Nos testes nos quais as amostras não são entalhadas (como no presente trabalho), uma fração maior de fibras poderia produzir um número maior de defeitos ou vazios e a resistência ao impacto medida pode até representar um valor menor que o real. No teste em que é feito entalhe na amostra, este é o maior defeito, sendo que a propagação da trinca é dificultada por uma fração maior de fibras. ${ }^{[6]}$

Nem sempre uma adesão mais intensa na interface fibra-matriz levará a uma maior resistência ao impacto, pois um "golpe" na interface não irá liberar a fibra da matriz e se a adesão for muito forte a "trinca" (microfibrilamento) pode se propagar pela matriz. Se a adesão não for muito forte, a fibra é liberada (mecanismo "pulled out") e a energia do impacto é absorvida. ${ }^{[6]}$

$\mathrm{Na}$ realidade, o desenvolvimento de termorrígidos mais resistentes deve levar a um balanceamento de propriedades. Uma modificação na matriz pode aumentar a resistência ao impacto, mas também aumentar a absorção de água. Pode, ainda, deslocar a transição vítrea para maiores temperaturas, mas por outro lado pode tornar o material mais quebradiço. Já a modificação química das fibras pode melhorar a adesão fibra-matriz.

A seguir estão mostradas algumas fotomicrografias obtidas por MEV após o ensaio de Impacto do tipo Izod das amostras de polímero termofixo fenólico (Figura 3 (a)), de polímero termofixo lignina-fenol (Figura 3 (b)), compósito lignina-

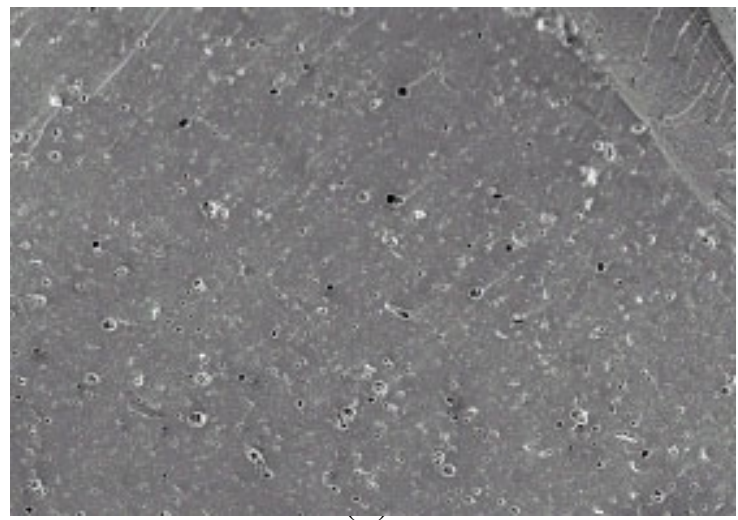

Figura 3. Fotomicrografias obtidas por MEV com ampliação de $200 \mathrm{X}$ : (a) polímero termofixo fenólico; (b) polímero termofixo ligninafenol. 
fenol/bagaço 1,5 cm (Figura 4 (a)) e compósito fenólico/sisal $3 \mathrm{~cm}$ (Figura 4 (b)).

Observa-se que os polímeros termofixos fenólico e lignina-fenol (Figura 3) apresentam microvazios, sendo que o polímero termofixo fenólico (Figura 3 (a)) apresenta maior quantidade de microvazios, os quais são mais evidentes. Observa-se também que estes polímeros termofixos apresentam morfologia de fratura do tipo frágil, com ausência de deformação plástica (a qual é observada em termoplástico). ${ }^{[9]}$

É importante ressaltar que normalmente quanto menor a quantidade de microvazios, melhores são as propriedades mecânicas do material. A presença de microvazios na resina curada, em quantidade acima de $20 \%$ do volume do material é provavelmente responsável por diminuir a resistência da resina. Os microvazios aparecem porque quando a massa molar aumenta, os resíduos de água já presentes na resina e a água que pode ser produzida durante a reação de cura, tornam-se insolúveis na resina curada e separam-se, ocorrendo então a vaporização, ocasionando domínios na matriz curada denominados de microvazios. ${ }^{[10]}$

Os microvazios podem agir como concentradores de tensão, reduzindo a capacidade de transporte da carga e a capacidade de absorção de energia do compósito. ${ }^{[11]}$

Na Figura 4 (a) observa-se que o compósito lignina-fenol com fibras de bagaço $(1,5 \mathrm{~cm})$ como reforço apresenta certa adesão entre as fibras e a matriz, pois as fibras não estão "soltas", sugerindo que sofreram quebra durante o ensaio de impacto. Observa-se que este compósito apresenta fibras que sofreram certa deformação (localizadas

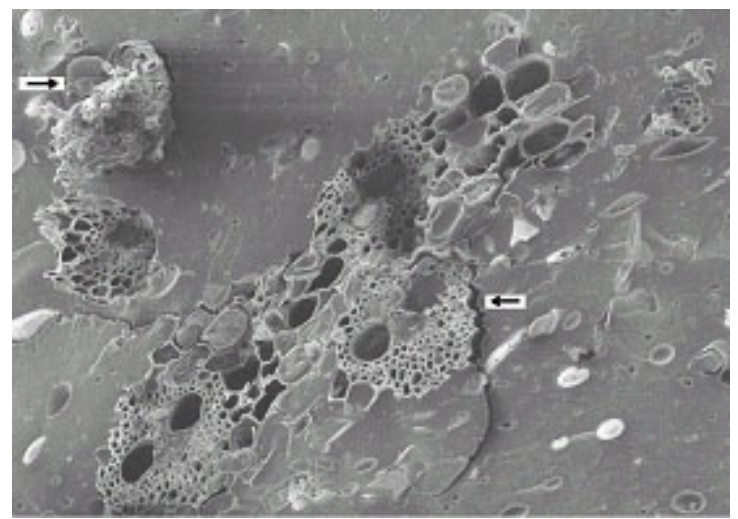

(a) no canto superior esquerdo). Observa-se ainda a ocorrência de propagação de fratura ao redor de fibras (localizada no centro da fotomicrografia).

Sabe-se que fibras celulósicas possuem arranjos (disposição) celulares que podem desviar a trajetória da trinca. Portanto em compósitos com essas fibras, a trinca não possui uma trajetória reta porque ela se desloca em volta das células das fibras e finalmente pára. ${ }^{[12]}$

A Figura 4 (b) apresenta a fratura do compósito fenólico com fibras de sisal $(3 \mathrm{~cm})$ após o ensaio de impacto, na qual observa-se vários mecanismos de fratura, tais como quebra de fibra (quando há certa adesão), propagação de fratura em volta da fibra e também o mecanismo "pullout", ou seja, fibras são liberadas da matriz quando a adesão é pouco intensa. Observa-se também que as fibras de sisal não estão recobertas pela resina (polímero fenólico), indicando pequena adesão matriz-fibra.

Quando a ligação matriz-fibra (interface) é fraca pode ocorrer uma diminuição da resistência à oxidação por facilitar a exposição da fibra e ainda, estimular a oxidação no interior do compósito. ${ }^{[13]}$

As fibras de curauá foram submetidas à uma solução de $\mathrm{NaOH} 10 \%$ e depois utilizadas na moldagem dos compósitos de matriz fenólica e lignina-fenol. Esse tratamento é denominado de mercerização, sendo muito utilizado para tratar fibras celulósicas, melhorando as características adesivas das superfícies das fibras devido a remoção de impurezas naturais e artificiais das superfícies. Portanto, a tensão superficial e consequentemente a molhabilidade ("wettability") das fibras mercerizadas se torna mais alta, melhorando também a ligação através de uma forma mecânica de entrela-

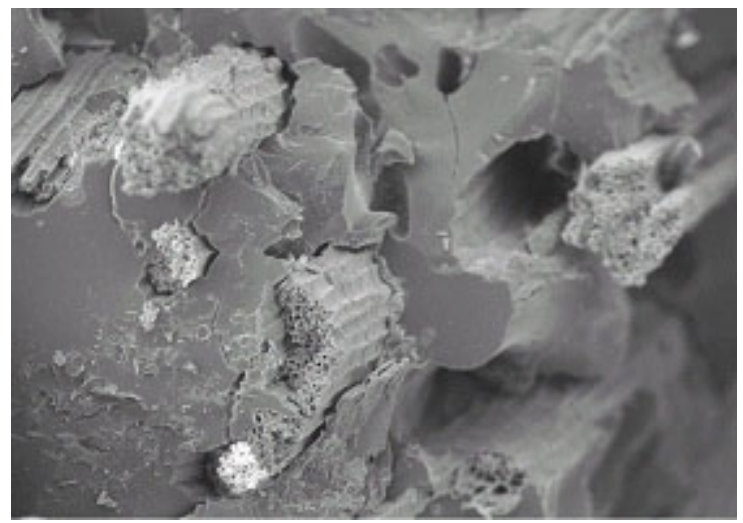

(b)

Figura 4. Fotomicrografias obtidas por MEV com ampliação de $200 \mathrm{X}$ : (a) compósito lignina-fenol/fibras de bagaço 1,5 cm; (b) compósito fenólico/fibras de sisal $3 \mathrm{~cm}$. 
Tabela 2. Resultados do Ensaio de Impacto Izod dos Polímeros Fenólicos e Compósitos contendo Fibras de Curauá tratadas com $\mathrm{NaOH}$ (solução $10 \%$ ).

\begin{tabular}{lc}
\hline \multicolumn{1}{c}{ Material } & $\begin{array}{c}\text { Resistência ao Impacto } \\
(\mathbf{J} / \mathbf{m})\end{array}$ \\
\hline $\begin{array}{l}\text { Polímero Termofixo Fenólico } \\
\text { Compósito Fenólico/Fibra }\end{array}$ & 12,8 \\
$\begin{array}{l}\text { Curauá (NaOH) } \\
\text { Polímero Termofixo } \\
\text { Lignina-fenol }\end{array}$ & 65,5 \\
$\begin{array}{l}\text { Compósito Lignina-fenol/Fibra } \\
\text { Curauá (NaOH) }\end{array}$ & 13,3 \\
\hline
\end{tabular}

çamento entre a matriz e a superfície rugosa das fibras. A mercerização também proporciona a desagregação das fibras (desfibrilamento), ou seja, o desdobramento do feixe de fibras em fibras menores, aumentando assim a área superficial efetiva disponível para o contato com a matriz líquida. Tem-se conhecimento que muitos compósitos nos quais foram utilizadas fibras mercerizadas, as propriedades mecânicas foram superiores àqueles nos quais foram utilizadas fibras não-tratadas. ${ }^{[14]}$

De acordo com a Tabela 2 observa-se que os compósitos fenólico e lignina-fenol contendo fibras de curauá tratadas com $\mathrm{NaOH}$ (solução a 10\%) apresentaram aumento nos valores de resistência ao impacto em relação aos respectivos polímeros termofixos fenólico e lignina-fenol (matriz fenólica e lignina-fenol).

\section{Conclusão}

Analisando-se as fotomicrografias realizadas por MEV observou-se que os compósitos contendo fibras de bagaço e os compósitos contendo fibras de sisal apresentaram menor quantidade de microvazios em relação às matrizes poliméricas (polímeros termofixos fenólico e lignina-fenol).

De acordo com os resultados do ensaio de impacto e MEV dos compósitos contendo fibras de sisal pode-se afirmar que estes apresentaram poucas regiões com adesão e muitas regiões nas quais as fibras foram liberadas (mecanismo "pullout") pelo impacto, revelando menor adesão. Assim, pode-se concluir que a adesão não foi homogênea por todo o material. Portanto, dando prosseguimento ao trabalho decidiu-se realizar tratamento das fibras de sisal com o objetivo de se melhorar a adesão fibra/matriz; já que para os compósitos fenólico e lignina-fenol contendo fibras de curauá tratadas com $\mathrm{NaOH}$ ocorreu um aumento nos valores da resistência ao impacto, ou seja, a desagregação destas fibras através do tratamento melhorou a interação da superfície da fibra com a matriz polimérica, facilitando a adesão na interface fibra-matriz. Também como tentativa de se melhorar a adesão interfacial fibra-matriz tem-se por objetivo realizar o tratamento de todas as fibras com ar ionizado, para posteriormente moldar os compósitos. Já foram realizados testes iniciais utilizando-se fibras de curauá tratadas com ar ionizado na moldagem de compósitos fenólicos, os quais indicaram ser viável este tratamento.

Porém nem sempre uma melhoria na adesão promove aumento na resistência ao impacto. $\mathrm{O}$ ideal seria uma combinação de propriedades para se obter compósitos resistentes e que apresentem reprodutibilidade de propriedades durante os testes ou ensaios mecânicos.

\section{Agradecimentos:}

À FAPESP (processo 97/06800-4) e ao CNPq. À INCOMAR (Indústria e Comércio Marques Ltda) pelo fornecimento do sisal. Ao Prof. Dr. Elias Hage Jr. e ao Roberto S. Yamakawa (DEMAUFSCar) pela realização dos ensaios de impacto.

\section{Referências Bibliográficas}

1. Rozman, H. D. (et al). - The Effect of Lignin and Surface Activation on the Mechanical Properties of Rubberwood-Polypropylene Composites. Journal of Wood Chemistry and Technology, v.18, n.4, p.471-490 (1998).

2. Nothenberg, M. - Cresce o Interesse pelo Uso de Fibras Naturais. Anuário Brasileiro do Plástico, p.6-15 (1996).

3. Clegg, D. W.; Collyer, A. A. - The Structure and Properties of Polymeric Materials. The Institute of Materials, British Library, London, p.123-124 (1993).

4. Dailey, T.H. Resorcinol-Modified Phenolics Reduce Flame, Smoke, Toxicity. Plastics Engineering, p. 33-36 (1989). 
5. Paiva, J. M. F. - Compósitos Lignocelulósicos: Matrizes Poliméricas de Resinas Fenólicas Reforçadas com Fibras de Bagaço de Cana-deAçúcar. São Carlos, Dissertação (Mestrado). Instituto de Química de São Carlos (Área Interunidades), Universidade de São Paulo, p.94. (1997)

6. Elias, H. G. - Macromolecules. 2.ed. New York, USA, Plenum Press, v.1, v.2, p.455-457, p.1173-1179. (1984)

7. Leão, A. L.; Tan, I. H.; Caraschi, J. C. - Curaua Fiber-A Tropical Natural Fiber from Amazons Potential and Applications in Composites. In: International Conference on Advanced Composites ICAC 98. Edited by: Yasser Gowayed, Faissal Abdel-Hady; Hurghada, Egypt, 15-18 december (1998).

8. Joseph, K. (et. al). - Influence of Interfacial Adhesion on the Mechanical Properties and Fracture Behaviour os Short Sisal Fibre Reinforced Polymer Composites. Eur. Polym. J. , v.32, n.10, p. 1243-1250 (1996).
9. Sawyer, L. C.; Grubb, D. T. - Polymer Microscopy, London, Chapman and Hall, p. 134, 219 (1994).

10. Brown, J. R.; St John, N. A. - Fire-Retardant Low-Temperature-Cured Phenolic Resins and Composites. Trip, v.4, n.12, p.416-420 (1996).

11. Lin, T. L.; Jang, B. Z. - Fracture Behavior of Hybrid Composites Containing Both Short and Continuos Fibres. Polymer Composites, v.11, n.5, p.293 (1990).

12. Chand, N.; Verma, S.; Rohatgi, P. K. - Tensile, Impact and Moisture Studies of Sisal-Polyester Composites. Trop. Sci., v.27, p.215-221 (1987).

13. Ju, C. P.; Murdie, N. - Microstructure of Pitch Fiber-Phenolic/ CVI Matrix Carbon-Carbon Composite. Materials Chemistry and Physics, v. 34, p.244-250 (1993).

14. Bisanda, E. T. N. - The Manufature of Roofing Panels from Sisal Fibre Reinforced Composites. Journal of Materials Processing Technology, v.38, p.369-380 (1993). 